\title{
Sex Differences in Attributions and Learned Helplessness ${ }^{1}$
}

\author{
Jacquelynne Eccles Parsons, ${ }^{1}$ Judith L. Meece, Terry F. Adler, and \\ Caroline M. Kaczala \\ Department of Psychology, The University of Michigan
}

This investigation assessed the hypothesis that girls are more likely to be learned helpless in math than boys. Students in grades 5 through 11 completed questionnaires assessing their causal attributions for success and failure in mathematics, their self-concepts of math ability, and their expectations for both current and future success in math. Results indicated that sex differences in attributions depended on the type of methodology used (open-ended or rank-ordered questions). The most consistent difference involved the differential use and ranking of ability, skills, and consistent effort. No sex differences were found in either students' perceptions of their own math ability or in their current achievement expectations. Girls, however, rated their future expectations slightly lower than did boys. Taken together, these results provide little support for the hypothesis that girls are generally more learned helpless in mathematics than are boys.

Competence and confidence in learning mathematics have been identified as critical mediators of both educational and occupational choices. Mathematical skills are important for admission to many college majors, for most professional occupations, and, increasingly, for many computerized technical occupations as well (see Brush, 1980; Fox, Brody, \& Tobin, 1980). Yet female students are less likely than male students to take advanced high school and college math courses. Considerable attention has been directed toward understanding the biological, psychological, and sociocultural factors contributing to this problem (for recent reviews see Fox et al., 1980; Parsons, Adler, Futterman, Goff, Kaczala, Meece, \& Midgley, in press; Wittig \& Petersen, 1979). In this study we examine the rele-

\footnotetext{
${ }^{1}$ Correspondence should be sent to J. E. Parsons, Department of Psychology, University of Michigan, Ann Arbor, MI 48109.
} 
vance of learned helplessness theories for explaining the relative lack of achievement and participation of women in mathematical areas.

As originally proposed by Seligman (1975), learned helplessness follows from a perception of little or no control over aversive events. In a recent reformulation of this theory, Abramson, Seligman, and Teasdale (1978) suggest that the inferences or attributions a person makes for this perceived lack of control are critical determinants of learned helplessness.

Dweck and her colleagues have extended the work of Seligman to achievement settings and have studied the achievement cognitions of "learned helpless" and "mastery-oriented" children. In these studies learned helplessness refers to the behavior of children who readily give up or show a steady decline in the effectiveness of the problem-solving strategies they use when confronted with failure. Mastery-oriented children, on the other hand, show increased persistence or improved performance in the face of failure (Dweck, 1975; Dweck \& Goetz, 1977; Dweck \& Reppucci, 1973).

Dweck's research further suggests that the differential responses of these children (to failure) are associated with different interpretations of the achievement situation. Mastery-oriented children place more emphasis on motivational factors as determinants of their outcomes than do helpless children; that is, mastery-oriented children are more likely to attribute failure to a lack of effort, a variable cause perceived as under one's control. Learned helpless children, on the other hand, are more likely to blame their failure on uncontrollable external factors; and when they do take responsibility, they are more likely to attribute failure to a lack of ability, an uncontrollable internal factor. The implication of such attributions is that failure is perceived as insurmountable and unavoidable.

Many studies have examined possible attributional differences underlying learned helplessness (e.g., Diener \& Dweck, 1978; Dweck \& Reppucci, 1973; Klein, Fencil-Morse, \& Seligman, 1976; Rholes, Blackwell, Jordan, \& Walters, 1980; Tennen \& Eller, 1977; Weisz, 1979). In each of these studies, the attribution of failure to external stable factors or to a lack of ability led to increased helplessness, defined in terms of impaired performance or decreased persistence. In contrast, attributions to variable situational factors or variable controllable internal factors such as task difficulty or lack of effort did not produce learned helplessness.

These studies point to the importance of attributional processes as mediators of learned helplessness. To the extent that the attributional patterns of males and females differ in the manner described above, females should be more likely to exhibit learned helpless behaviors. Many researchers believe that sex differences in attributional patterns emerge with sufficient regularity to warrant this conclusion. It has been reported repeatedly that males tend to attribute their successes to internal stable causes and their failures to external or unstable causes. 
Females tend to reverse this pattern, taking personal responsibility for their failures, but not for their successes (e.g., Bar-Tal, 1978; Dweck \& Bush, 1976; Frieze, Fisher, Hanusa, McHugh, \& Valle, 1978; Parsons, Ruble, Hodges, \& Small, 1976). However, these trends are not replicated across all studies, and in many instances results are mixed and equivocal. In addition, few studies have actually assessed attributional differences related either to achievement tasks presented in naturalistic settings or to school subject areas. Thus, caution must be observed in making generalizations or predictions based on these data.

More consistent findings might emerge in studies focusing specifically on mathematics performance. For example, there has been some speculation that sex differences in attributional patterns are most marked for sex-typed achievement tasks (see Deaux, 1976; Frieze et al., 1978). As early as seventh grade, the majority of boys and girls stereotype mathematics as more useful for males (e.g., Brush, 19.80; Fennema \& Sherman, 1977; Parsons et al., in press; Sherman, 1980; Stein \& Smithells, 1969). In addition, mathematics is an area of achievement that has yielded fairly consistent sex differences on a set of variables assumed to be mediated by attributional processess. Compared to male students, females have lower achievement expectancies in mathematics, lower self-concepts of their math ability, and slightly higher levels of math anxiety (cf. Brush, 1980; Fennema \& Sherman, 1977, 1978; Parsons et al., in press; Meece, Note 1). It has been suggested that these differences might result from a sex-differentiated attributional pattern (Dweck \& Licht, 1980; Wolleat, Pedro, Becker, \& Fennema, 1980).

The present study employs a multimethod approach to test the hypothesis that girls are more likely to exhibit characteristics of learned helplessness in mathematics. Past research has defined and measured learned helplessness in a variety of ways. If learned helplessness in mathematics is more common in females than in males, then there should be sex differences in the achievement expectancies, self-concepts of ability, and causal attribution patterns related to mathematics. For each of these constructs, the pattern of responses given by female students should indicate that they have less perceived control over their performance and achievement in mathematics than the males students.

\section{METHOD}

Three hundred and thirty students ( 180 females and 150 males) from fifth to eleventh grade were given a questionnaire which included, among other measures, four attributional measures and questions assessing their expectations for their performance in both current and future math courses and their self-concept 
of mathematical ability. ${ }^{2}$ Each of these measures was specific to mathematics.

\section{Open-Ended Attributions}

The children's attributions for success and failure on a math test were assessed using two open-ended attributional questions, which took the following form: "Think of the last math test you did well/not well on. Why do you think you did so well/poorly?" The coding system for these questions was developed in two phases. First, a set of codes comparable to the categorical codes commonly used for open-ended attributions in other studies was selected (Bar-Tal \& Darom, 1979; Elig \& Frieze, 1975; Frieze \& Snyder, 1980). Second, a random set of responses was inspected. Skill or specific knowledge was mentioned frequently in these responses. Given the importance of the distinction between controllable and uncontrollable factors, we felt it important to code ability and skill as separate causes. Therefore, skill or knowledge was added as an independent category, resulting in the following 11 categories: math knowledge or skills, longterm or consistent effort, immediate or short-term effort, task ease or difficulty, math ability, interest in math, physical or emotional state at time of test, teacher factors, classroom factors, luck, and unclassifiable. An overview of the coding criteria can be obtained from the first author. Coders had little difficulty mastering the coding system and were able to categorize responses with $90 \%$ or better intercoder consistency. The uncodable category included "don't know" responses as well as unclassifiable responses; it was rarely used ( $N=41$ out of 619 coded responses).

These categories were further collapsed, based on theoretical rational, to form broader categories. Two such analyses were performed. First, internal and external attribution responses were contrasted. For this comparison, math skill, consistent effort, immediate effort, ability, interest, and physical or emotional state comprised the internal category, while task ease or difficulty, teacher factors, classroom factors, and luck comprised the external category. Analyses

${ }^{2}$ The full questionnaire is discussed in more detail in Parsons, Adler, Futterman, Goff, Kaczala, Meece, and Midgley (in press), available from the first author. The full questionnaire contained the Personal Attributes Questionnaire, a shortened version of the Intellectual Achievement Responsibility Scale (IAR) (Crandall, Katkovsky, \& Crandall, 1956), a measure of sex-role identity, and the following six additional constructed scales: sex-typing of ability in mathematics, utility of math for one's goals, incentive value of math, importance of math, cost of effort needed to do well, and perceptions of parents' beliefs regarding one's math abilities. While the IAR has been used to assess learned helplessness by Dweck and her colleagues, it is not specific to mathematics. Since the sex effects on the IAR were not significant and since the IAR is not specific to mathematics, it will not be discussed further in this report. 
were performed to test whether or not girls would be more likely to attribute either their math successes or math failures to external causes than would boys. The next set of comparisons was more complex. Here three categories of responses were formed and then contrasted: (a) internal controllable, (b) internal uncontrollable, (c) external uncontrollable. For this comparison, math skill, consistent effort, and immediate effort comprised the internal controllable category; ability, physical/emotional state, and interest comprised the internal uncontrollable category; task difficulty, teacher and classroom factors, and luck comprised the external uncontrollable category. This set of categories was used to test the hypothesis that girls would be more likely to attribute their math successes and failures to uncontrollable causes than would boys.

\section{Rank-Order Attributional Ratings}

To provide both a more complete picture of the children's attributional patterns and a more sensitive test of the sex difference hypotheses, two closeended attributional questions were included. Originally, in keeping with the suggestions of Elig \& Frieze (1979), we planned to use a scale format in which children rate the importance of each of the eight attributional causes commonly used by children in explaining achievement outcomes (Bar-Tal \& Darom, 1979; Frieze \& Snyder, 1980). However, pilot testing indicated that children did not make reliable attributional judgments using this format. Consequently, we shifted to a rank-order procedure which would provide us with an estimate of the relative importance of each of the eight causes. While some power is lost using this procedure, the gain in reliability was judged to be critical.

The children were given two rank-ordering attribution questions - one for success and one for failure. They were asked to recall a previous success (failure) on a math test and to select the most important cause from a list of the following attributions: ability, teacher help, parent help, interest, consistent effort, immediate effort, task difficulty, and mood or unstable internal state at time of test. The attributional causes were given as a brief statement (e.g., I am good at math, I studied hard for the test). The children were then asked to select the second most important cause, the third most important reason, and so on until they had ranked all eight. Skill was not included in this set, since it had not been used in previous studies and this questionnaire was constructed prior to receiving responses to the open-ended questions described above.

Responses to these attribution questions were used in two types of analyses to test the specific sex difference predictions related to the learned helplessness hypothesis. First, the responses were analyzed as independent attributional statements. They were also used to assign subjects to broader classes based on the pattern of their attributions (i.e., a low expectancy, mixed, or high expectancy pattern). A high expectancy pattern consisted of the following: ranking 
ability or consistent effort among the most important causes of success (ranked in the top four); ranking insufficient effort, task difficulty, mood, or lack of teacher help as among the most important causes of failure; and ranking lack of ability as an unimportant cause of failure (ranked in the bottom four). A low expectancy pattern consisted of the following: ranking immediate effort, task ease, mood, or teacher help as among the most important causes of success; and ranking lack of ability, lack of consistent effort, or dislike of math as among the most important causes of failure.

\section{Attributional Variables}

Children's beliefs regarding their expectations for their performance in current and future math courses were assessed using the Likert-type scales developed by Parsons et al. (in press). The following three scales, each composed of three or more items, were used: Math Ability (item example: How good at math are you? Not at all good/Very good; alpha $=.80$ ), Current Expectancies for Math (item example: How well do you think you will do in your math course this year? Very poorly/Very Well; alpha $=.83$ ), Future Expectancies for Math (item example: How well do you think you'll do in your mathematics course next year? Not at all well/Very well; alpha $=.79$ ).

\section{RESULTS AND DISCUSSION}

\section{Open-Ended Attributions}

Chi-square analyses were used to test for sex effects on the open-ended attributions. The responses of boys and girls were submitted to two chi-square analyses - one for their responses to success and one for their responses to failures. The results are depicted in Table I. In response to the open-ended questions, girls were more likely than boys to attribute both their successes and failures to skill, while the boys were more likely than girls to attribute both their successes and failures to effort. In addition, skill and immediate effort were the most preferred attributions of both boys and girls (used by approximately $80 \%$ of the sample.) Ability was rarely mentioned by either boys or girls.

Collapsing across the categories, there were no sex differences in the mention of internal versus external attributions for either success or failure. In addition internal causes were, by a large margin, the most frequent causal explanations used by both boys and girls for success and failure (used by approximately $80 \%$ of the sample). There were also no sex differences in the use of internal controllable and internal uncontrollable explanations for either success or failure. 
Table I. Frequencies of Open-Ended Attributions for Success and Failure

\begin{tabular}{|c|c|c|c|c|}
\hline & \multicolumn{2}{|c|}{ Success $a$} & \multicolumn{2}{|c|}{ Failure $^{b}$} \\
\hline & $\begin{array}{c}\text { Females } \\
(N=171)\end{array}$ & $\begin{array}{c}\text { Males } \\
(N=135)\end{array}$ & $\begin{array}{c}\text { Females } \\
(N=175)\end{array}$ & $\begin{array}{c}\text { Males } \\
(N=138)\end{array}$ \\
\hline \multirow[t]{2}{*}{ Skill or math knowledge } & 81 & $37 c$ & 54 & $26^{c}$ \\
\hline & $47.4 \%$ & $27.4 \%$ & $30.9 \%$ & $18.8 \%$ \\
\hline \multirow{2}{*}{ Consistent effort } & 9 & $15^{d}$ & 6 & $15^{d}$ \\
\hline & $5.3 \%$ & $11.1 \%$ & $3.4 \%$ & $10.9 \%$ \\
\hline \multirow[t]{2}{*}{ Immediate effort } & 48 & 48 & 66 & $71 d$ \\
\hline & $28.1 \%$ & $35.6 \%$ & $37.7 \%$ & $51.4 \%$ \\
\hline \multirow[t]{2}{*}{ Task difficulty } & 13 & 12 & 8 & 5 \\
\hline & $7.6 \%$ & $8.9 \%$ & $4.6 \%$ & $3.6 \%$ \\
\hline \multirow[t]{2}{*}{ Natural ability } & 4 & 5 & 1 & 2 \\
\hline & $2.3 \%$ & $3.7 \%$ & $.6 \%$ & $1.4 \%$ \\
\hline \multirow{2}{*}{ Interest in math } & 2 & 3 & 2 & 1 \\
\hline & $1.2 \%$ & $2.2 \%$ & $1.1 \%$ & $.7 \%$ \\
\hline \multirow{2}{*}{$\begin{array}{l}\text { Mood or unstable internal } \\
\text { state }\end{array}$} & 2 & 2 & 6 & 6 \\
\hline & $1.2 \%$ & $1.5 \%$ & $3.4 \%$ & $4.3 \%$ \\
\hline \multirow{2}{*}{ Teacher } & 4 & 2 & 12 & 2 \\
\hline & $2.3 \%$ & $1.5 \%$ & $6.9 \%$ & $1.4 \%$ \\
\hline \multirow[t]{2}{*}{ Classroom } & 0 & 1 & 2 & 1 \\
\hline & & $.7 \%$ & $1.1 \%$ & $.7 \%$ \\
\hline \multirow{2}{*}{ Luck } & 2 & 1 & 0 & 1 \\
\hline & $1.2 \%$ & $.7 \%$ & & $.7 \%$ \\
\hline \multirow[t]{2}{*}{ Don't know or unclassified } & 6 & 9 & 18 & 8 \\
\hline & $3.6 \%$ & $6.6 \%$ & $10.3 \%$ & $5.8 \%$ \\
\hline
\end{tabular}

These data suggest that females and males are equally, and predominantly, internal for both success and failure in mathematics. Both see success and failure experiences as largely within their control; they differ primarily in their relative propensity to mention skill versus effort as their preferred internal controllable attribution. Skill and effort differ in their future stability.

\section{Rank-Order Data}

The results of median tests (Siegel, 1956) on the ranked data showed significant sex differences for only two of the eight reasons the children were asked to rank. Boys ranked ability as a more important cause of success than did girls (median test $=9.16, d f=1, p=.003$, population median $=5.0$ ), while girls ranked consistent effort as a more important cause of success than the boys (median test $=16.39, d f=1, p<.001$, population median $=4.0$ ). Exactly the reverse pattern emerged for failure. Boys ranked the importance of lack of ability as a cause for 
failure lower than did girls (median test $=8.8, d f=1, p=.003$, population median $=6.0$ ), while they ranked the importance of consistent effort higher than the girls (median test $=4.93, d f=1, p=.03$, population median $=4.0$ ). There were no significant differences $(p>.05)$ in how boys and girls ranked the importance of teacher or parent help, interest, immediate effort, task difficulty, or mood at the time of the test for either success or failure. For success, immediate effort (population median $=2.0$ ) and teacher help (population median $=3.0$ ) were ranked as the two most important causal attributions, while parent help (population median $=7.0$ ) was ranked as the least important by both boys and girls. For failure, lack of immediate effort (population median $=1.0$ ) and task difficulty (population median $=2.0$ ) were ranked as the two most important causal attributions, while lack of parent help (population median $=7.0$ ) was ranked as least important by both boys and girls.

We next used the rank-ordered data to classify children as exhibiting a high expectancy attributional pattern $(N=68)$ or a low expectancy attributional pattern $(N=121)$. Children who did not fall into either of these categories were classified as exhibiting a mixed attribution pattern $(N=120)$. Females were no more likely than males to exhibit either the high expectancy pattern or the low expectancy pattern.

\section{Student Attitudes}

Sex differences on the three attitude scales were assessed with analyses of variance. There were no significant sex effects on either the ability scale or the current expectancy scale. The girls did, however, have lower future expectancy scores than did the boys $(F=7.79, d f=1,327, p<.01)$.

\section{CONCLUSIONS}

Four conclusions are clear from our results: First, the overall pattern of sex differences and attributions depends on the methodology used. Few differences were consistent across method; the most consistent effects are the nonsignificant differences. Second, despite the fact that mathematics is a sex-typed subject area, the effects that did emerge are quite small and often occur on attributions judged to be of low importance. Third, the most consistent significant effects involve the differential use of the internal attributions for both success and failure, with girls, in comparison to boys, tending to use the more unstable internal attributions for success and the more stable internal attributions for failure. Fourth, little support was found for the hypothesis that girls are more learned helpless than boys for mathematics. 
The last two conclusions warrant more detailed discussion. In both the ranked and open-ended responses, the major sex differences occured with the use of the various internal attributions. However, the pattern of sex effects for success is quite different across the two measures. In ranking attributional causes for success, girls gave a higher rank to effort than boys, while boys gave a higher rank to ability. Thus, the rank-order data suggest that girls view their successes as more controllable but less stable than do boys. This pattern, however, was not evident in open-ended responses. On this measure girls mentioned skills and knowledge more frequently than boys as reasons for their successes, suggesting that girls attribute success in mathematics to more stable factors than boys (assuming that skill or knowledge is a stable attribute and that effort is unstable). Both sexes weigh the importance of effort and skill acquistion as quite high relative to the other possible causal attributions, and neither sex sees math success primarily as a consequence of ability.

The pattern associated with failure is more consistent across the two measures. In both sets of analyses, girls rated either lack of ability or lack of knowledge as a more important cause of failure than did boys, while boys rated lack of effort as a more important cause than did girls. However, ability was not seen as one of the most important reasons for failure in either analysis. On the forced choice question items, both boys and girls ranked immediate effort and task difficulty as the most important reasons for failure. On the open-ended items, natural ability was rarely mentioned by either boys or girls. Furthermore, these data do not indicate that girls see failure as more stable than do boys. Lack of skill may be seen as an unstable modifiable attribute; if so, the open-nded responses suggest that girls see failure as modifiable. Since skill or knowledge was not one of the choices on the ranking list, we do not know how it would have been ranked in comparison to natural ability. Nor do we know how the children conceptualize the term "ability" or "not very smart." Recent work by Hess, King, and Holloway (Note 2) suggests that a sizable proportion of both parents and children do not consider ability to be a stable attribution.

Attributional differences between the sexes may have their most marked effect on the children's perceptions of the task demands inherent in future, more advanced math courses, rather than on the children's responses to experiences in their current math courses. The girl who views consistent effort (or skill and knowledge generally acquired through consistent effort) as an important determinant of success in mathematics might have lower expectations for her future success precisely because future courses are considered even more difficult, demanding more effort to continue to succeed (Parsons et al., in press). In support of this hypothesis, girls in this sample do have lower future expectancies, but do not have lower expectancies for success in their current math course.

These data suggest that girls drop math for reasons other than learned helplessness. Learned helplessness has been defined in a variety of ways using 
both attributional patterns and behavioral response to failure. Dweck and Licht (1980) based their conclusion that girls are more learned helpless than boys on the following attributional pattern: greater likelihood of attributing their failure to lack of ability and less likelihood of attributing their failure to motivational or external causes. This pattern is not fully supported by our data. While our results provide partial support for sex differences in use of ability as a causal explanation of failure, we found that very few boys or girls reported lack of ability as an important cause of failure. In addition, the sex difference in attributing failure to lack of ability did not emerge consistently across our two measures. With regard to differential motivational or external attributions for failure, we found that in the rank-ordering measure boys ranked consistent effort as more important for failure. But across both measures boys and girls were equally likely to attribute their failures to lack of immediate effort, task difficulty, and inadequate teaching. In addition, these causes were given the highest rating of importance by both sexes.

Learned helplessness has also been defined in terms of perceived control of one's successes and failures. Perceived control can be assessed by looking at the use of such attributions as immediate effort, consistent effort, and skill or knowledge. On these attributions, we found no clear pattern of sex differences.

Finally, learned helplessness has been defined in terms of either the general pattern of attributions to external causes for success and internal causes for failure, or by a more general pattern of attributions associated with high versus low expectancies. We found no significant sex differences on either of these patterns.

In conclusion, our results suggest that we should exercise great caution in building models of sex differences in mathematics achievement around attributions. The differences do not present a consistent pattern. In addition, the psychological significance of the differences that do exist are only just beginning to be explored.

\section{REFERENCE NOTES}

1. Meece, J. L. Sex differences in achievement-related affect. Paper presented at the meeting of the Society for Research in Child Development, Boston 1981.

2. Hess, R. D., King, D. R., \& Holoway, S. D. Causal explanations for high and low performance in school: Some contrasts between parents and children. Paper presented at the meeting of the Society for Research in Child Development, Boston 1981.

\section{REFERENCES}

Abramson, L. Y., Seligman, E. P., \& Teasdale, J. D. Learned helplessness in humans: Critique and reformulation. Journal of Abnormal Psychology, 1978, 87, 49-74.

Bar-Tal, D. Attributional analysis of achievement-related behavior. Review of Educational Research, 1978, 48, 259-271. 
Bar-Tal, D., \& Darom, E. Pupils' attributions for success and failure. Child Development, $1979,50,264-267$.

Brush, L. R. Encouraging girls in mathematics: The problem and the solution. Cambridge, Mass.: Abt Books, 1980.

Crandall, V. C., Katkovsky, W., \& Crandall, V. J. Children's belief in their own control of reinforcement in intellectual-academic achievement situations. Child Development, $1956,36,91-109$.

Deaux, K. Sex: A perspective on the attribution process. In J. H. Ickes, \& R. F. Kidd (Eds.), New directions in attribution research (Vol. 1). Hillsdale, N.J.: Lawrence Erlbaum, 1976.

Diener, C. I., \& Dweck, C. S. An analysis of learned helplessness: Continuous change in performance, strategy, and achievement cognitions following failure. Journal of Personality and Social Psychology, 1978, 36, 451-462.

Dweck, C. S. The role of expectations and attributions in the alleviation of learned helplessness. Journal of Personality and Social Psychology, 1975, 31, 674-685.

Dweck, C. S., \& Bush, E. Sex differences in learned helplessness: 1. Differential debilitation with peer and adult evaluations. Developmental Psychology, 1976, 12, 147-156.

Dweck, C. S., \& Goetz, T. E. Attributions and learned helplessness. In J. H. Harvey, W. J. Ickes, \& R. F. Kidd (Eds.), New directions in attribution research (Vol. 2), Hillsdale, N.J.: Lawrence Erlbaum, 1978.

Dweck, C. S., \& Licht, B. G. Learned helplessness and intellectual achievement. In J. Garber \& M. E. P. Seligman (Eds.), Human helplessness: Theory and application. New York: Academic Press, 1980.

Dweck, C. S., \& Reppucci, N. D. Learned helplessness and reinforcement responsibility in children. Journal of Personality and Social Psychology, 1973, 25, 109-116.

Elig, T. W., \& Frieze, I. H. A multidimensional scheme for coding and interpreting perceived causality for success and failure events: The Coding Scheme of Perceived Causality (CSPC). JSAS Catalog of Selected Documents in Psychology, 1975, 5, 313. (Ms. No. 1069)

Elig, T. W., \& Frieze, I. H. Measuring causal attributions for success and failure. Journal of Personality and Social Psychology, 1979, 37, 621-634.

Fennema, E., \& Sherman, J. Sex-related differences in mathematics achievement, spatial visualization and affective factors. American Educational Research Journal, 1977, 14, 51-71.

Fennema, E., \& Sherman, J. Sex-related differences in mathematics achievement and related factors: A further study. Journal for Research in Mathematics Education, 1978, 9, 189-203.

Fox, L. H., Brody, L., \& Tobin, D. (Eds.) Women and the mathematical mystique. Baltimore: Johns Hopkins University Press, 1980.

Frieze, I. H., Fisher, J., Hanusa, B., McHugh, M., \& Valle, V. Attributing the causes of success and failure: Internal and external barriers to achievernent in women. In J. Sherman \& F. Denmark (Eds.), Psychology of women: Future directions of research. New York: Psychological Dimensions, 1978.

Frieze, I. H., \& Snyder, H. N. Children's beliefs about the causes of success and failure in school settings. Journal of Educational Psychology, 1980, 72, 186-196.

Klein, D. C., Fencil-Morse, E., \& Seligman, M. E. P. Learned helplessness, depression, and the attribution of failure. Journal of Personality and Social Psychology, 1976, 33, 11-26.

Parsons, J. E., Adler, T. F., Futterman, R, Goff, S. B., Kaczala, C. M., Meece, J. L., \& Midgley, C. Expectancies, values and academic behaviors. In J. T. Spence (Ed.), Perspectives on achievement and achievement motivation. San Francisco: Freeman, in press.

Parsons, J. E., Ruble, D. N., Hodges, D. L., \& Small, A. W. Cognitive-developmental factors in emerging sex differences in achievement-related expectancies. Journal of Social Issues, $1976,32,47-61$.

Rholes, W. S., Blackwell, J., Jordan, C., \& Walters, C. A developmental study of learned helplessness. Developmental Psychology, 1980, 16, 616-624. 
Seligman, M. E. P. Helplessness: Depression, development, and death. San Francisco: Freeman, 1975.

Sherman, J. Mathematics, spatial visualization, and related factors: Changes in girls and boys, grades 8-11. Journal of Educational Psychology, 1980, 72, 476-482.

Siegel, S. Nonparametric statistics for the behavioral sciences. New York: McGraw-Hill, 1956.

Stein, A. H., \& Smithells, T. Age and sex differences in children's sex role standards about achievement. Developmental Psychology, 1969, 1, 252-259.

Tennen, H., \& Eller, S. J. Attributional components of learned helplessness and facilitation. Journal of Personality and Social Psychology, 1977, 35, 265-271.

Weisz, J. R. Perceived control and learned helplessness among mentally retarded and nonretarded children: A developmental analysis. Developmental Psychology, 1979, 15, 311-319.

Wittig, M. A., \& Petersen, A. C. (Eds.). Sex-related differences in cognitive functioning: Developmental issues. New York: Academic Press, 1979.

Wolleat, P. L., Pedro, J. D., Becker, A. D., \& Fennema, E. Sex differences in high school students' causal attributions of performance in mathematics. Journal of Research in Mathematical Education, 1980, 11, 356-366. 